\section{Ratio scales of acid sourness}

\section{HOWARD R. MOSKOWITZ*}

\section{U.S. Army Natick Laboratories, Natick, Massachusetts 01760}

Experiments were conducted to assess the relation between concentration, or $\mathrm{pH}$, and the perceived sourness of 24 acids. The psychophysical functions for soumess conform to the power relation $\mathrm{S}=\mathrm{kC}^{\mathrm{n}}$ which relates sensory intensity, $\mathrm{S}$, to physical concentration, C. Averaged across the 24 acids, the exponent for soumess was 0.85 for both molar and percentage concentrations, and about -1.70 for $\mathrm{pH}$ concentration. The intercept, $\mathrm{k}$, which is a measure of relative soumess, differed across acids. The particular measure used to designate the concentration of an acid markedly influenced its magnitude and rank order of sourness.

The measurement of soumess is an attractive problem in taste psychophysics because sourness is the only primary taste quality for which a necessary chemical stimulus has been established, namely the $\mathrm{H}+$ ion. The number of such ions in solution is not sufficient, however, to predict sourness (Harvey, 1920).

A number of studies have appeared that attempted to evaluate how factors other than the $\mathrm{H}+$ ion affect the perceived intensity of the sour taste. For example, Becker and Herzog (1907) showed that the normality of acids, the number of functional $\mathrm{H}+$ ions per molecule, did not predict sourness since acids were not equally sour at equal normalities. For equal normalities, their rank ordering of sourness, from high to low, was $\mathrm{HCl}, \mathrm{HNO}_{3}$, lactic, acetic, and butyric acids. Paul (1922) reported that acids matched for soumess differed both in molar concentration and in the number of free $\mathrm{H}+$ ions. In a review of the early work on sourness, Taylor (1928) suggested that the ability of an acid to penetrate living tissue was also an important variable that contributed to the degree of acid sourness. Beatty and Cragg (1935) argued that sourness could be measured by the "objective" technique of determining the amount of buffer required to bring the $\mathrm{pH}$ of selected acids to a preset $\mathrm{pH}$ value. They chose acids that matched the soumess of a reference level of $\mathrm{HCl}$, performed the titrations, and reported estimates of relative sourness.

Psychophysical scales of sourness have been reported by Corin (1888), Paul (1922), and Pangborn (1963). Corin used category scales to determine whether acids initially matched for sourness were equally sour after equivalent dilutions were made. His results suggest that the equivalent dilutions did not produce equal decreases in apparent soumess. Paul and Pangborn described equal-sourness contours across several organic acids, analogous to the

\footnotetext{
*Eugene Zanella prepared the stimulus solutions and measured their $\mathrm{pH}$ values, William Gantz assisted in running the experiment and analyzing the results, and Dr. Bonald Ganchrow read the manuscript and gave many helpful suggestions to clarify its contents.
}

Group B: Sugar Derived Acids equal-loudness contours measured in audition. A replot of their sourness matches in log-log coordinates reveals that the relative growth functions of the different acids may be power functions. Similar direct matches between the sweetness of sugars (Cameron, 1947) also produced equal-sweetness functions that appear as straight lines in log-log coordinates (see Fig. 6).

The direct psychophysical scaling of soumess was undertaken by Beebe-Center and his students, and a standard scale of sourness was proposed (Beebe-Center, 1949; Beebe-Center \& Waddell, 1948). Using a "fractionation" procedure, they determined concentrations of tartaric acid that were judged half as sour as a set of standard concentrations. In presenting Table 1 Stimuhs Concentrations

\begin{tabular}{|c|c|c|c|c|c|c|}
\hline \multirow{2}{*}{$\begin{array}{c}\text { Acid } \\
\text { (Molecular Weight) }\end{array}$} & \multicolumn{3}{|c|}{ Molar and $\mathrm{pH}$} & \multicolumn{2}{|c|}{ Concentrations } & \\
\hline & 1 & 2 & 3 & 4 & 5 & 6 \\
\hline
\end{tabular}

Group A : Saturated Acids

1. Lactic (90)

2. Tartronic (120)

3. DL Malic (134)

4. L Malic (134)

5. Tartaric (150)

\section{Dihydroxy}

Tartaric (182)

7. Citric (192)

8. Succinic (118)

9. L Glutamic (147)

10. N Acetyl L Glutamic (189)

11. Glutaric (132)

12. 3,3 Dimethyl Glutaric (160)

13. Ribonolactone (148)

14. Glucono $\Delta$ Lactone (178)

15. Galactono $\Delta$ Lactone (178)

16. Galactouronic (194)

17. Phytic (660)

Group C: Ascorbic

18. D Ascorbic (176)

19. L Ascorbic (176)

Group D: Unsaturated Acids 20. Sorbic (112)

21. Fumaric (116)

22. Levulinic (116)

23. Itaconic (130)

24. Trimellitic (210) $\mathrm{M}=.003$

$\begin{aligned} \mathbf{M} & =.003 \\ \mathbf{p H} & =3.6 \\ \mathbf{M} & =.003 \\ \mathbf{p H} & =2.9 \\ \mathbf{M} & =.003 \\ \mathbf{p H} & =3.3 \\ \mathbf{M} & =.003 \\ \mathbf{p H} & =3.4 \\ \mathbf{M} & =.003 \\ \mathbf{p H} & =3.2 \\ \mathbf{M} & =.003 \\ \mathbf{p H} & =3.1 \\ \mathbf{M} & =.003 \\ \mathbf{p H} & =3.3 \\ \mathbf{M} & =.003 \\ \mathbf{p H} & =3.7 \\ \mathbf{M} & =.003 \\ \mathbf{p H} & =3.6 \\ \mathbf{M} & =.003 \\ \mathbf{p H} & =3.3 \\ \mathbf{M} & =.0015 \\ \mathbf{p H} & =3.9 \\ \mathbf{M} & =.003 \\ \mathbf{p H} & =\mathbf{3 . 2} \\ \mathbf{8} & \\ \mathbf{M} & =\end{aligned}$

$\mathrm{M}=.05$

$\mathrm{pH}=3.7$

$\mathrm{M}=.025$

$\mathbf{p H}=\mathbf{3 . 0}$

$\mathrm{M}=.025$

$\begin{aligned} \mathrm{M} & =.02 \\ \mathrm{pH} & =\mathbf{3 . 4}\end{aligned}$

$\mathrm{M}=.025$

$\mathrm{pH}=2.9$

$\begin{aligned} \mathrm{M} & =.003 \\ \mathrm{pH} & =2.5\end{aligned}$

.006

3.4

.006

2.8

.006

3.1

.006

3.2

.006

3.0

.006

2.8

.006

3.1

.006

3.6

.006

3.5

.006

3.1

.003

3.7

.006

3.1

.1

3.6

.05

2.8

.05
.4

3.4
.05

2.05

.006

.0125

3.2

.0125

2.6

.0125

3.0

.0125

3.0

.0125

2.7

.0125

2.6

.0125

3.0

.0125

3.4

.0125

3.4

.0125

2.9

.0125

3.0

$\stackrel{.02}{2.9}$

2.8

.2

3.4

-1
2.7

.1

3.3

.1

.0125

2.0

$\begin{array}{rll}\mathbf{M} & =.00625 & .0125 \\ \mathbf{p H} & =3.4 & 3.3 \\ \mathbf{M} & =.00625 & .0125 \\ \mathrm{pH} & =3.5 & \mathbf{3 . 3}\end{array}$

.025

3.2

.025

3.2

.4
3.3

.2

2.6

2

.2

2.5

.025

.025

.05

.05

2.3

.05

2.7

.05

2.8

.05

2.4

.05

2.2

.05

2.7

.05

3.1

.025

.025

2.05

2.5

$\stackrel{.05}{3.0}$

.05

3.0

.8

4

2.4

.4

3.0

2.3

.05

1.7

2.9

2.8

$M=\quad \begin{array}{lll}.003125 & .00625 & .0125\end{array}$

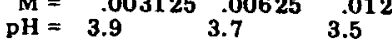

$M=.00625 \quad .0125 \quad .025$

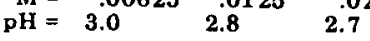

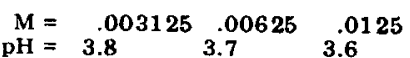

3.7

$\begin{aligned} \mathrm{M} & =.003 \\ \mathrm{pH} & =3.4\end{aligned}$

.006

3.6

$\mathbf{M}=.0015$

3.3

.0125

3.1

$\begin{array}{lcr}.025 & .05 & .1 \\ 3.4 & 3.3 & 3.1 \\ .025 & .05 & .1 \\ 3.0 & 2.9 & 2.7 \\ .0125 & .025 & .05 \\ 2.6 & 2.5 & 2.3\end{array}$


Table 2

Parameters of the Power Relation (S $=\mathbf{K C N}$ ) Between Soumeas and (a) Molarity, (b) Percentage Concentration, and (c) $\mathrm{pH}$

\begin{tabular}{|c|c|c|c|c|c|}
\hline \multirow[b]{2}{*}{ Acid } & \multicolumn{2}{|c|}{ Least Squares (a } & and b) & \multicolumn{2}{|c|}{ Least Squares (c) } \\
\hline & $\begin{array}{c}\text { Exponent } \\
\mathbf{N}\end{array}$ & $\begin{array}{c}\text { Molar } \\
\text { Intercept } \\
\mathbf{K}\end{array}$ & $\begin{array}{c}\text { Percentage } \\
\text { Intercept } \\
\mathbf{K} \\
\end{array}$ & $\begin{array}{c}\text { pH } \\
\text { Exponent } \\
\mathbf{N}\end{array}$ & $\begin{array}{c}\mathbf{p H} \\
\text { Intercept } \\
\mathbf{K} \\
\end{array}$ \\
\hline 1. Lactic & 0.84 & 165.2 & 26.1 & -1.46 & 5.31 \\
\hline 2. Tartronic & 0.85 & 360.4 & 43.6 & -1.56 & 5.01 \\
\hline 3. DL Malic & 0.77 & 263.4 & 35.7 & -1.62 & 5.81 \\
\hline 4. L Malic & 0.72 & 204.1 & 31.5 & -1.40 & 5.24 \\
\hline 5. Tartaric & 0.82 & 274.0 & 29.7 & -1.32 & 4.58 \\
\hline 6. Dlhydroxy Tartaric & 0.81 & 370.2 & 35.3 & -1.18 & 4.16 \\
\hline 7. Citric & 0.72 & 201.0 & 23.9 & -1.39 & 5.09 \\
\hline 8. Succinic & 0.76 & 199.4 & 30.5 & -1.39 & 5.62 \\
\hline 9. Glutamic & 0.71 & 51.5 & 7.6 & -2.87 & 10.43 \\
\hline 10. N Acetyl L Glutamic & 0.55 & 24.1 & 4.8 & -1.10 & $\mathbf{3 . 6 5}$ \\
\hline 11. Glutaric & 1.59 & 114.0 & .19 & -2.53 & 9.51 \\
\hline 12. 3,3 Dimethyl Glutaric & 0.94 & 5360 & 39.6 & -2.84 & 9.45 \\
\hline 13. Ribonolactone & 1.21 & 53.0 & 2.0 & -2.38 & 9.01 \\
\hline 14. Glucono Lactone & 0.64 & 86.1 & 13.6 & -1.40 & 5.08 \\
\hline 15. Galactono Lactone & 0.82 & 30.2 & 2.8 & -1.90 & 6.81 \\
\hline 16. Galactouronie & 0.69 & 128.2 & 16.6 & -1.52 & 5.36 \\
\hline 17. Phytic & 0.78 & 134.7 & 51.3 & -1.23 & 4.13 \\
\hline 18. D Ascorbic & 0.91 & 171.8 & 12.6 & -1.55 & 5.69 \\
\hline 19. L Ascorbic & 0.94 & 262.9 & 17.7 & -2.16 & 7.73 \\
\hline 20. Sorbic & 0.84 & 179.6 & 23.6 & -1.27 & 5.08 \\
\hline 21. Fumaric & 0.86 & 400.9 & 48.7 & -1.64 & 5.60 \\
\hline 22. Levulinic & 0.73 & 114.4 & 19.1 & -1.60 & 6.20 \\
\hline 23. Itaconic & 1.03 & 706.0 & 50.3 & -2.25 & 7.94 \\
\hline 24. Trimellitic & 0.93 & 538.1 & 31.7 & -1.59 & 5.17 \\
\hline
\end{tabular}

evidence for his power law, Stevens (1957) noted that the functions generated by the fractionation procedure approximated power functions. In particular, when plotted in log-log coordinates, the relation between scale value and molar concentration of tartaric acid was a straight line with slope (exponent) of approximately 1.0 . Other studies using direct magnitude estimation of sensory magnitude, in which the $\mathrm{O}$ adjusts numbers to match taste intensity, have produced different exponents, from low values around 0.5 (Feallock, 1965, with $\mathrm{HCl}$; Kocher \& Fisher, 1969, with citric acid) to higher values around 0.9 (Meiselman, 1968, with $\mathrm{HCl}$ ) and 1.0 (Moskowitz, 1968, with tartaric acid).

The present study was undertaken to assess the relationship between perceived sourness and concentration, or $\mathrm{pH}$ for 24 different acids. Most of the acids were carbohydrate derivatives, although several other organic acids were evaluated as well.

\section{PROCEDURE}

All of the acids used were reagent-grade (Fisher Chemical Corp., Nutritional Biochemicals Corp., Sigma Chemical Corp., or Eastman Organic Chemicals), and solutions were prepared from distilled and deionized water of $\mathrm{pH}$ 6.9-7.1. Each series of stimuli for an acid conformed to a geometric sequence of molar concentrations, with a ratio of $2: 1$ between successive concentrations. Table 1 presents the acids tested, with concentration expressed in molarity and $\mathrm{pH}(\mathrm{pH}$ measured with a Photovolt digital $\mathrm{pH}$ meter). the afternoon. No initial numerical the Os were instructed to assign numbers in proportion to apparent sourness. The number matches across all sessions were normalized through the inclusion of six standard solutions of citric acid in each session. The procedure of modulus normalization (Moskowitz, 1970a) was used to bring the absolute magnitudes of the judgments of each $\mathrm{O}$ into agreement with a preset level, without, however, altering the ratios of his magnitude estimates.

\section{RESULTS}

The numerical matches to sourness were analyzed with the concentration expressed as molarity, percentage-by-weight, and $\mathrm{pH}$. Molarity and percentage assess the overall amount of acid in solution, whereas $\mathrm{pH}$ is a logarithmic function of the number of $\mathrm{H}+$ ions in solution. For the same set of concentrations of a single acid, molarity and percentage may be related by a multiplicative constant, whereas $\mathrm{pH}$ must be independently measured.

Table 2 presents the relations obtained

In each of four experiments, 12 Os were given a series of $40-48$ acid concentrations, comprising several series of different acids. The acids were presented in irregular order, and the $O$ was instructed to taste the sample, write down his magnitude estimate of sourness, expectorate, and rinse with water. Each 0 participated in two sessions each day, once in the morning and once in modulus was assigned by the $\mathrm{E}$, and the standard was whatever solution in the series was first chosen by the $O$. Other than the interstimulus rinse, the $O$ was not constrained to follow any time pattern in sampling the stimuli. The Os were enlisted men at the U.S. Army Natick Laboratories, who were test volunteers.

The detailed instructions and the method of analysis have been presented previously (Moskowitz, 1970a, b). In brief, between sourness and three measures of concentration. The power function $\mathrm{S}=\mathrm{kC}^{\mathrm{n}}$ relating sourness $\mathrm{S}$ to concentration $\mathrm{C}$ was assumed adequate to represent the sourness function. Both exponent (slope) $\mathbf{n}$ and intercept $\mathrm{k}$ were calculated by a least-squares procedure after the judgments had been converted to logarithms. The corresponding sourness functions, plotted relative to molarity, are presented in Figs. 1-4. The coordinates are $\log -\log$ and the straight lines represent power functions whose exponents are given by the slopes of the lines. The mean exponent for sourness as a function of molarity and percentage is approximately 0.85 , suggesting that sourness grows as a negatively accelerating function of concentration.

The relation between $\mathrm{pH}$ and $\log$ sourness is also linear, but the mean slope

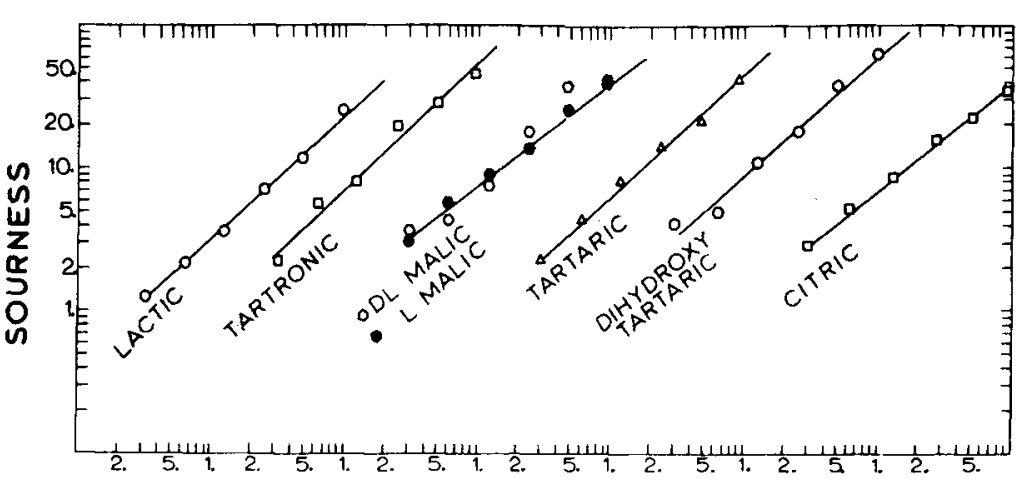

ACID MOLARITY $\times 1000$

Fig. 1. The relation between soumess and molarity for seven saturated acids. The coordinates are log-log, so that straight lines represent power functions. 


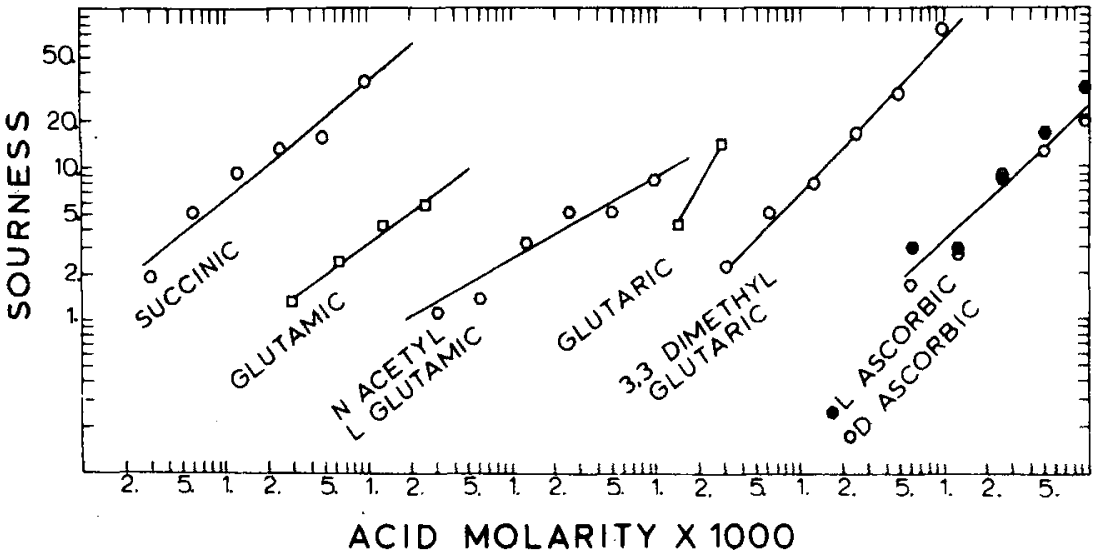

Fig. 2. Sourness functions for seven additional saturated acids. The coordinates are log-log. The ordinate values for glutaric acid have been shifted upward by one log unit.

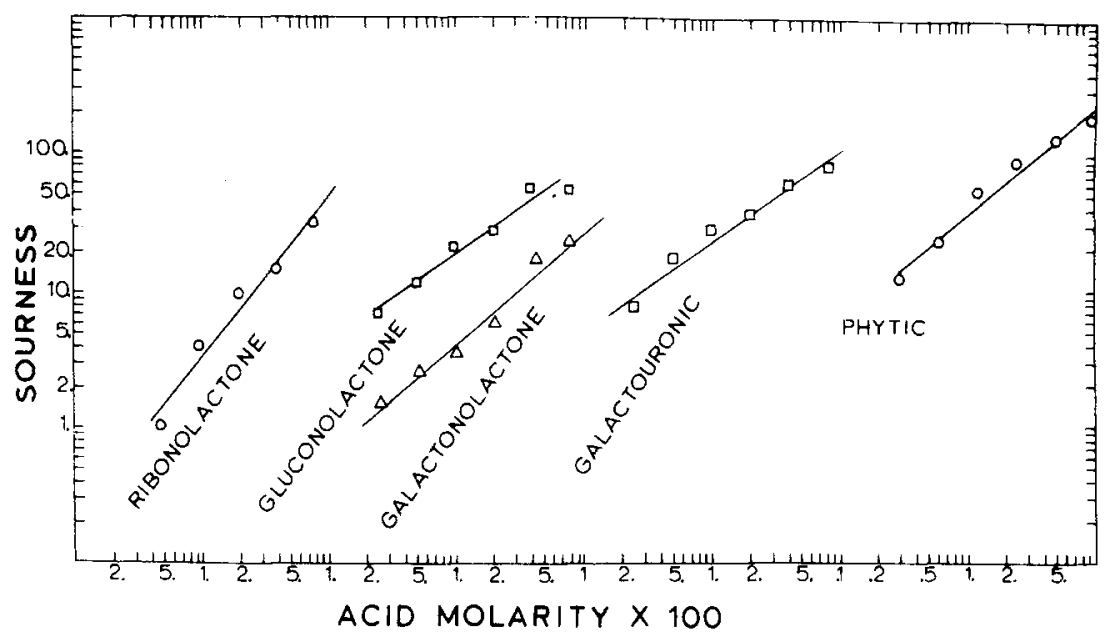

Fig. 3. Sourness functions for acids derived from sugars. The coordinates are log-log.

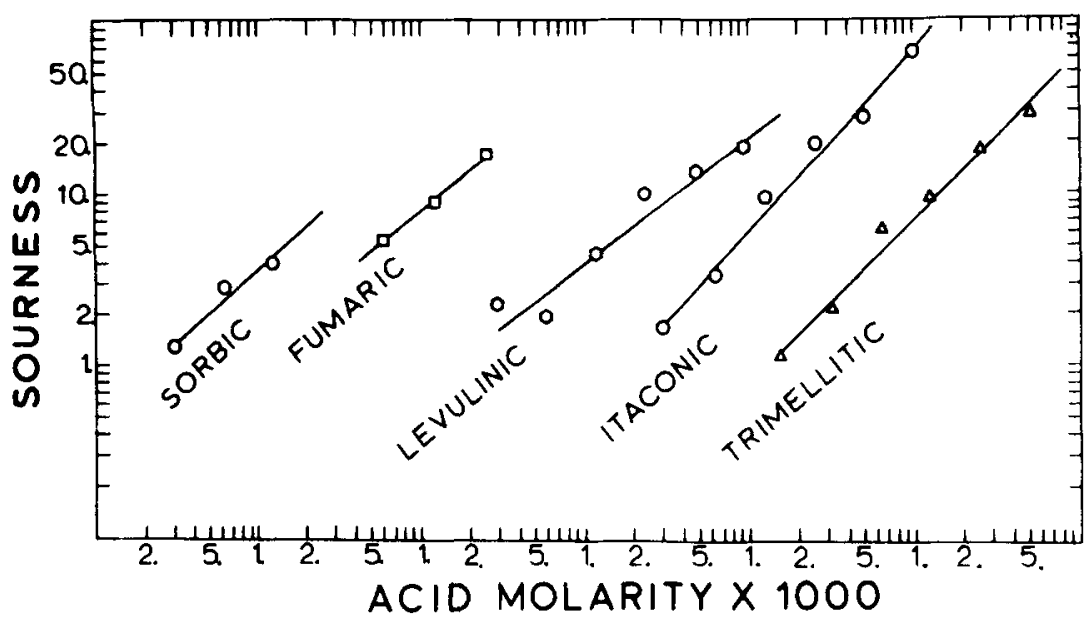

Fig. 4. Sourness functions for unsaturated acids. The coordinates are log-log.

is about -1.70 , suggesting that apparent sourness grows as an accelerating function of the concentration of the $\mathrm{H}+$ ion (high
$\mathrm{pH}$ indicates low concentrations of $\mathrm{H}+$ ion, and vice versa). The mathematical transformation from overall concentration to that of the $\mathrm{H}+$ ion decreases the effective range of concentration (abscissa). Therefore, the psychological range of sourness, which remains unchanged through the transformation, must fit a smaller range of concentrations. Hence the exponent for sourness must increase. Accelerating functions for taste intensity have already been reported for sweetness relative to the molarity of sugar, and saltiness relative to the molarity of $\mathrm{NaCl}$ (Moskowitz, 1968, 1970a, b; Stevens, 1969). In each case, the exponent was between 1.3 and 1.6.

\section{RELATIVE SOURNESS OF ACIDS}

The intercept $k$ of the power function relating sourness to concentration may be used as a measure of relative sourness across acids. Table 2 lists the numerical values of the intercepts of the 24 sourness functions when concentration is expressed as molarity, percentage, or $\mathrm{pH}$. These values relative to a standard acid (here citric acid) represent relative magnitudes of sourness at 1 molar, $1 \%$, or $\mathrm{pH}$ of 0 . Because the various soumess functions are diverging lines in $\log -\log$ coordinates, their logarithmic distances, which represent ratios of sourness, change continuously across concentration, and therefore the values in Table 2 pertain only to the concentrations given by the intercept.

In a previous study (Moskowitz, 1970a), the exponent for sugar sweetness was fixed at a representative value for 15 sugars, and therefore the sweetness functions of the various sugars became parallel lines in $\log -\log$ coordinates. As a result, the distance separating the functions was constant, and therefore across the entire continuum of concentration only one number was needed to characterize relative sweetness. In this study a similar analysis was made; the sourness exponent was fixed at 0.7 (for molarity and percentage), or -1.4 for $\mathrm{pH}$. These two exponents are rounded averages for the exponents of the citric acid standard used in all the sourness tests. Figure 5 shows the logarithms of the relative values (citric acid $=0.0$ ) of the intercepts for the 24 acid functions obtained with the three measures of concentration. The single number for each measure suffices to characterize relative sourness across different concentrations.

A number of relations between molecular structure and relative sourness may be obtained from Fig. 5:

(1) When $\mathrm{pH}$ is used as the measure of concentration, acids having lower molecular weight appear to be the more sour. There is no consistent relation, however, between molecular weight and relative soumess when the measure of 


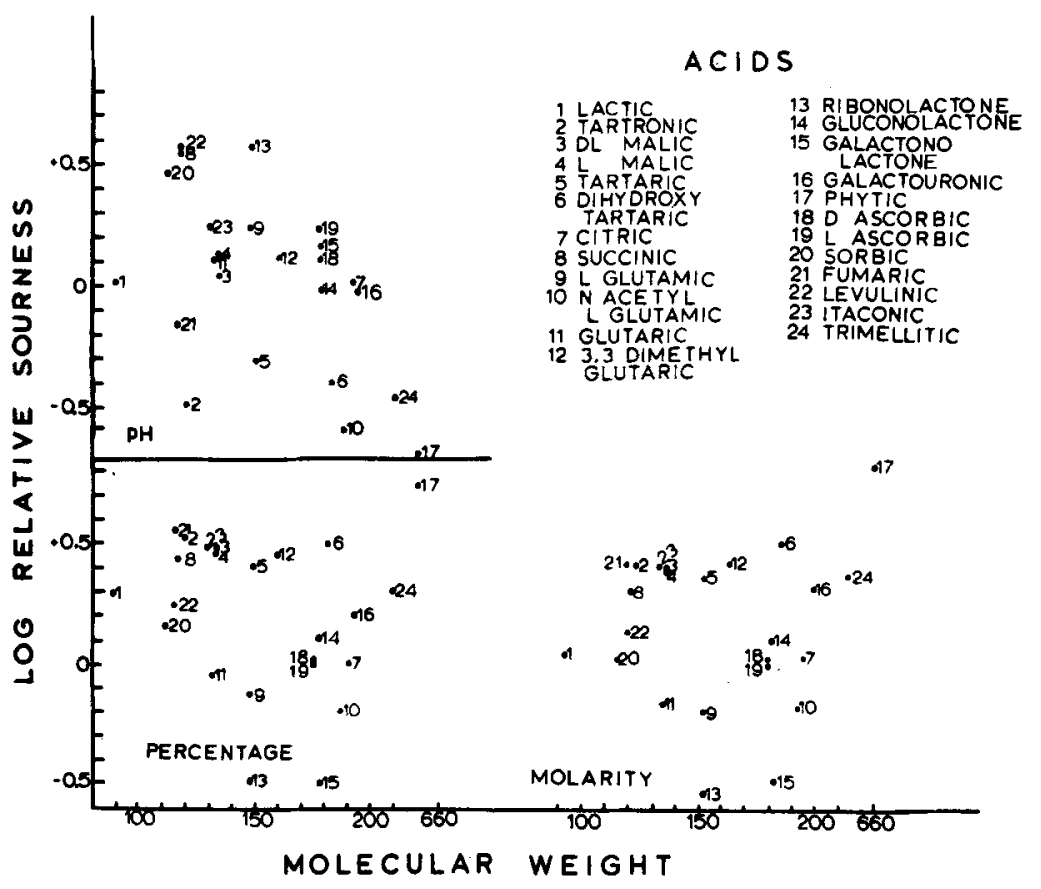

Fig. 5. The relation between sourness and molecular weight, when the measure of concentration is molarity, percentage-by-weight, and $\mathrm{pH}$.
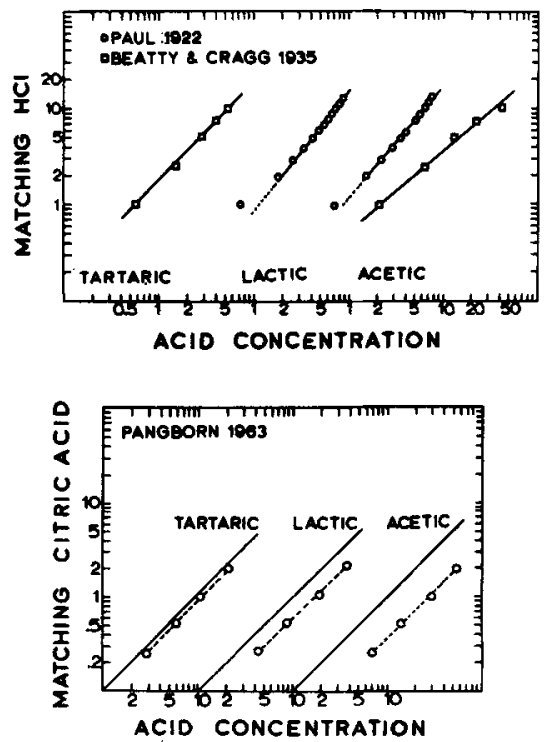

Fig. 6. Equal-sourness matches between acids obtained in previously reported studies.

concentration is either molarity or percentage by weight.

(2) The measure of concentration affects the order and magnitude of relative sourness. When molarity is the measure, the introduction of additional groups to a simple acid molecule makes the acid relatively more sour (e.g., tartaric vs dihydroxy tartaric acid, L glutamic vs sourness of one of the acids conforms to a power function, soumess of the rest do also. In other words, the two different types of matches, acid-acid, and acid-number, give results that are generally consistent. As a first approximation, therefore, the power law that describes the growth of sensory magnitude with physical intensity on more than two dozen continua (Stevens, 1957, 1969) appears to describe the growth function of apparent sourness.

\section{REFERENCES}

BEATTY, R. M., \& CRAGG, L. H. The sourness of acids. Journal of the American Chemical Society, 1935, 57, 2347-2351.

BECKER, C. T., \& HERZOG, R. O. Zur Kenntniss des Geschmackes. Zeitschrift für Physiologische Chemie, 1907, 52, 496-505.

BEEBE-CENTER, J. G. Standards for use of the gust scale. Journal of Psychology, 1949, 28, 411-419.

BEEBE-CENTER, J. G., \& WADDELL, D. A general psychological scale of taste. Journal of Psychology, 1948, 26, 517-524.

CAMERON, A. T. The taste sense and the relative sweetness of sugar and other sweet substances. Report 9 of the Sugar Research Foundation, New York, 1947.

CORIN, J. Action des acides sur le goût. Archives de Biologie, 1888, 8, 121-138.

FEALLOCK, J. B. Estimated magnitudes of taste under improved conditions of stimulus control. Unpublished doctoral dissertation, University of Virginia, 1965.

HARVEY, R. B. The relation between the total acidity, the concentration of the hydrogen ion, and the taste of acid solutions. Journal of the American Chemical Society, 1920, 42 712-714.

KOCHER, E. C., \& FISHER, G. L. Subjective intensity and taste preference. Perceptual \& Motor Skills, 1969, 28, 735-740.

MEISELMAN, H. L. Adaptation and cross-adaptation of the four gustatory qualities. Perception \& Psychophysics, 1968, $4,368-372$.

MOSKOWITZ, H. R. Scales of intensity for single and compound tastes. Unpublished doctoral dissertation, Harvard University, 1968.

MOSKOWITZ, H. R. Ratio scales of sugar sweetness. Perception \& Psychophysics, 1970a $7,315-320$.

MOSKOWITZ, H. R. Sweetness and intensity of artificial sweeteners. Perception \& Psychophysics, $1970 \mathrm{~b}, 8,40-42$.

PANGBORN, R. M. Relative taste intensities of selected sugars and organic acids. Journal of Food Science, 1963, 28, 726-733.

PAUL, T. Physikalische Chemie der Leb ensmittel. VI. Physikalische-chemische Untersuchungen über die sauere Geschmacksempfind ung. Zeitschrift für Elektrochemie, 1922, 28, 435-446.

STEVENS, S. S. On the psychophysical law. Psychological Review, 1957, 64, 153-181.

STEVENS, S. S. Sensory scales of taste intensity. Perception \& Psychophysics, 1969, 6, 302-308.

TAYLOR, N. W. Acid penetration into living tissue. Journal of General Physiology, 1928, $11,207-219$

(Accepted for publication August 21, 1970.) 